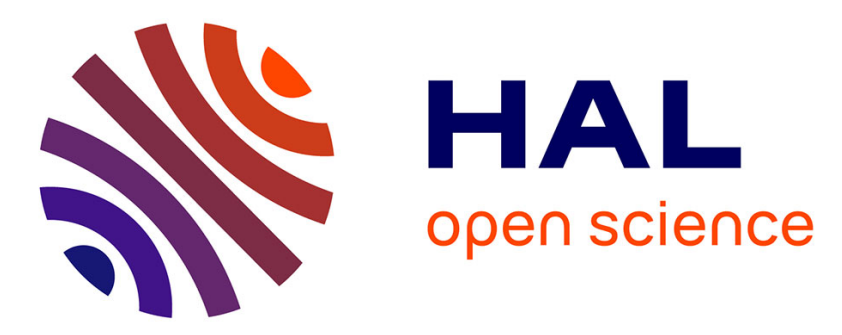

\title{
Manganese and rhenium-catalyzed selective reduction of esters to aldehydes with hydrosilanes
}

\author{
Duo Wei, Ruqaya Buhaibeh, Yves Canac, Jean-Baptiste Sortais
}

\section{To cite this version:}

Duo Wei, Ruqaya Buhaibeh, Yves Canac, Jean-Baptiste Sortais. Manganese and rhenium-catalyzed selective reduction of esters to aldehydes with hydrosilanes. Chemical Communications, 2020, 56 (78), pp.11617-11620. 10.1039/d0cc03580g . hal-02959788

\section{HAL Id: hal-02959788 \\ https://hal.science/hal-02959788}

Submitted on 18 Nov 2020

HAL is a multi-disciplinary open access archive for the deposit and dissemination of scientific research documents, whether they are published or not. The documents may come from teaching and research institutions in France or abroad, or from public or private research centers.
L'archive ouverte pluridisciplinaire HAL, est destinée au dépôt et à la diffusion de documents scientifiques de niveau recherche, publiés ou non, émanant des établissements d'enseignement et de recherche français ou étrangers, des laboratoires publics ou privés. 


\title{
Manganese and Rhenium-catalyzed Selective Reduction of Esters to Aldehydes with Hydrosilanes
}

Received 00th January 20xx,

\author{
Duo Wei, ${ }^{a, b}+$ Ruqaya Buhaibeh, ${ }^{b}+Y_{\text {ves }}$ Canac $^{b}$ and Jean-Baptiste Sortais*b,c
}

DOI: $10.1039 / \times 0 \times x 00000 x$

The selective reduction of esters to aldehydes, via the formation of stable alkyl silyl acetals, was, for the first time, achieved with both manganese, $-\mathrm{Mn}_{2}(\mathrm{CO})_{10}-$ and rhenium $-\mathrm{Re}_{2}(\mathrm{CO})_{10}$ - catalysts in the presence of triethylsilane as reductant. These two methods provide a direct access to a large variety of aliphatic and aromatic alkyl silyl acetals (30 examples) and to the corresponding aldehydes (13 examples) upon hydrolysis. The reactions proceeded in excellent yields and high selectivity at room temperature under photoirradiation conditions (LED, $365 \mathrm{~nm}, 40 \mathrm{~W}, 9 \mathrm{~h}$ ).

Functional group interconversion reactions are fundamental processes in synthetic chemistry. In this respect, the direct conversion of carboxylic acid esters to aldehydes represents a major but recurring challenge in organic synthesis. Indeed, due to the higher reactivity of aldehydes with respect to their ester precursors towards nucleophilic addition of hydride species, the undesired formation of alcohols resulting from over-reduction of aldehydes is generally difficult to avoid. Stoichoimetric reducing reagents involving bulky substituents, ${ }^{1}$ such as diisobutylaluminum hydride (DIBALH), ${ }^{2}$ have been widely employed, usually at low temperature but these reagents prove to be difficult to handle in both laboratorial and industrial scales, because of their dangerous nature. Therefore, the development of safer or/and greener catalytic processes is highly preferable and of primary interest.

In the field of heterogeneous catalysis, a few systems based on $\mathrm{Y}-\mathrm{Al}_{2} \mathrm{O}_{3}{ }^{3}, \quad \mathrm{Y}_{2} \mathrm{O}_{3}{ }^{4}, \mathrm{Mn} / \mathrm{Al}^{5}$ were developed for the direct hydrogenation of esters into aldehydes. However high reaction temperatures $\left(260-420^{\circ} \mathrm{C}\right)$ were generally required. As an alternative, catalytic reductions using hydrosilanes as a hydride source, i.e. via hydrosilylation, are more attractive from both selectivity and safety points of view. ${ }^{6}$ For example, Motoyama and coll. reported $\mathrm{Pd} / \mathrm{C}$ as catalyst for the hydrosilylation of

\footnotetext{
a.Dr. D. Wei, Univ Rennes, CNRS, ISCR - UMR 6226, F-35000, Rennes, France.

b.Dr. D. Wei, R. Buhaibeh, Dr. Y. Canac, Prof. Dr. J.-B. Sortais, LCC-CNRS, Université de Toulouse, CNRS, UPS, Toulouse, France, E-mail: jean-baptiste.sortais@lcctoulouse.fr

c. Prof. Dr. J.-B. Sortais, Institut Universitaire de France, 1 rue Descartes, F-75231 Paris Cedex 05, France.

+ These authors contributed equally to this work.

Electronic Supplementary Information (ESI) available: [details of any supplementary information available should be included here]. See DOI: 10.1039/x0xx00000x
}

esters to silyl acetals at $50{ }^{\circ} \mathrm{C}$ with 2.5 equiv. of $1,1,3,3-$ tetramethyldisiloxane (TMDS), the acetals being then easily converted to aldehydes after hydrolysis. ${ }^{7}$

In homogeneous catalysis, a limited number of systems capable of catalyzing the hydrosilylation of esters into aldehydes have been described. The first example, was reported by Piers and coll., involving the organocatalyst $\mathrm{B}\left(\mathrm{C}_{6} \mathrm{~F}_{5}\right)_{3}$ and $\mathrm{Ph}_{3} \mathrm{SiH}$ as reducing agent. ${ }^{8} \mathrm{~A}$ few examples were also described with noble metals such as palladium, ${ }^{9}$ ruthenium ${ }^{10}$ and iridium. ${ }^{11}$ On the other hand, only two catalysts involving Earth abundant metals were developed to date: a system based on cobaltdescribed by Michon and coll. ${ }^{12}$ and another involving iron described by our group. ${ }^{13}$

Manganese, which is also a $3 \mathrm{~d}$ metal standing as the third most abundant transition metal after iron and titanium, is attractive for the design of sustainable homogeneous catalysts. ${ }^{14}$ Lately, the use of manganese in (transfer)hydrogenation reactions of various unsaturated compounds has grown exponentially ${ }^{15}$ including the reduction of esters to alcohols. ${ }^{16}$ Meanwhile, manganese has also been proven to be effective in the hydrosilylation of carbonyl and carboxylic acid derivatives. ${ }^{17}$ In particular, it has been shown that esters could be selectively reduced to alcohols ${ }^{18}$ or to ethers. ${ }^{19}$

However, to the best of our knowledge, the hydrosilylation of esters into aldehydes remains unknown to date with manganese while only an example was described with rhenium. ${ }^{20}$ In the present contribution, we report thus the first effective Mn catalyzed reduction of esters to alkyl silyl acetals which can then be conveniently hydrolyzed to corresponding aldehydes. In addition, following our recent study on the rhenium-catalyzed reduction of carboxylic acids to aldehydes, ${ }^{21}$ the activity of the related rhenium complex $\operatorname{Re}_{2}(\mathrm{CO})_{10}$ is evaluated in this process and compared with that observed with its lighter congener $\mathrm{Mn}_{2}(\mathrm{CO})_{10}$.

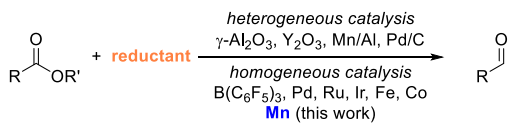

Scheme 1. Catalytic selective reduction of carboxylic esters to aldehydes. 
Based on our previous studies on the hydrosilylation of carboxylic acid derivatives, ${ }^{13}, 21-22$ we firstly reacted methyl 2naphthylacetate 1a with $\mathrm{Et}_{3} \mathrm{SiH}$ (4 equiv.) in the presence of $\mathrm{Mn}_{2}(\mathrm{CO})_{10}$ (5.0 mol\%) under irradiation (LED, $365 \mathrm{~nm}, 4 * 10 \mathrm{~W}$ ) in toluene at room temperature (Table 1). ${ }^{23}$ To our delight, within $3 \mathrm{~h}, 1 \mathrm{a}$ was converted to the corresponding alkyl silyl acetal $\mathbf{2 a}$ obtained as a major product in $92 \%$ conversion and $82 \%$ selectivity, while only $18 \%$ of the undesired silyl ether $\mathbf{3 a}$ was formed simultaneously due to over reduction (entry 1 ). Lowering the amount of silane from 4 to 1.1 equiv. induced a decrease of the conversion (from $92 \%$ to $60 \%$ ) but enhanced significantly the selectivity toward the desired product $\mathbf{2 a}$ (entries 2-4). With only 1.1 equiv. of $\mathrm{Et}_{3} \mathrm{SiH}$, in $9 \mathrm{~h}, 2 \mathrm{2a}$ was obtained in $89 \%$ NMR yield with an excellent selectivity $(90 \%$ conversion, ratio 2 a: 3 a over $>95$ : $<5$, entry 6 ).

Table 1. Optimization of the parameters for the reduction of methyl 2-naphthylacetate $1 a^{\text {aa }}$

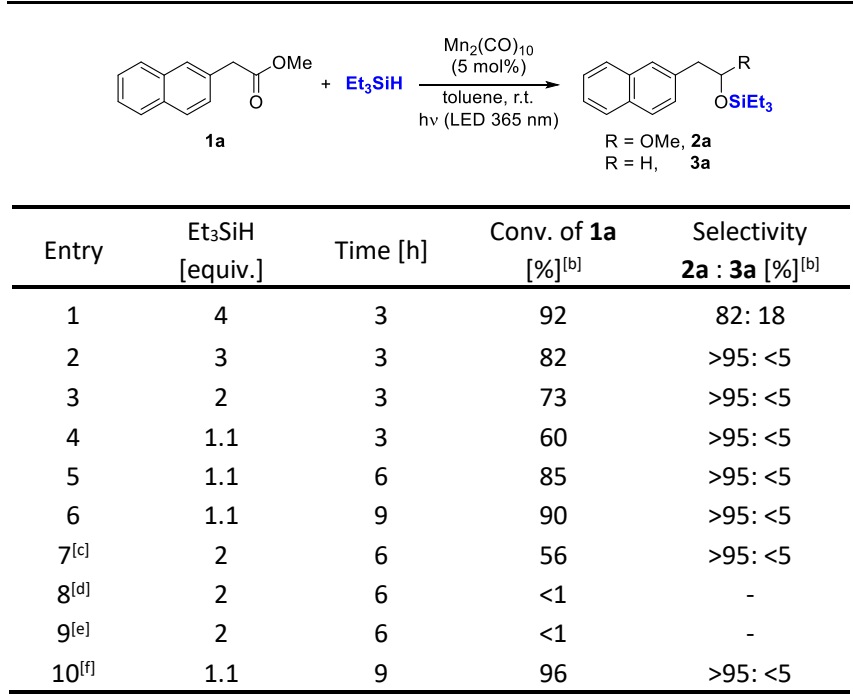

[a] General conditions: In a Schlenk tube, $\mathrm{Mn}_{2}(\mathrm{CO})_{10}$ (4.9 mg, $5.0 \mathrm{~mol} \%$ ), toluene (0.5 mL), Et $\mathrm{E}_{3} \mathrm{SiH}$, and $1 \mathrm{a}(50 \mathrm{mg}, 0.25 \mathrm{mmol})$ were added in that order, then stirred under irradiation (LED $365 \mathrm{~nm}, 40 \mathrm{~W}$ ) at r.t. (c.a. $30^{\circ} \mathrm{C}$ ); [b] Conversion of 1a and yields of $2 \mathrm{a}$ and $3 a$ detected by ${ }^{1} \mathrm{H}$ NMR; [c] irradiation $(400-800 \mathrm{~nm}, 30 \mathrm{~W})$; [d] in the dark; [e] at $100{ }^{\circ} \mathrm{C} ;[\mathrm{f}] \mathrm{Re}_{2}(\mathrm{CO})_{10}(0.5 \mathrm{~mol} \%)$

As in the case of carboxylic acids, ${ }^{21-22}$ the nature of the silane was found to be crucial for the selectivity of the reaction (See S.I. Table S1, entries 8-13). Indeed, the use of the secondary silane $\mathrm{Et}_{2} \mathrm{SiH}_{2}$ led to partial conversion of 1a (41\%) with the formation of a mixture of products $\mathbf{2 a}$ and $\mathbf{3} \mathbf{a}$ in a ratio 49: 51 . On the contrary, $\mathrm{Ph}_{2} \mathrm{SiH}_{2}, \mathrm{PhSiH}_{3}$ and TMDS reversed the selectivity of the reaction and $\mathbf{3 a}$ was detected as the sole product. With other tertiary silanes such as $\mathrm{Ph}_{3} \mathrm{SiH}$ and $\mathrm{MePh}_{2} \mathrm{SiH}$, no reaction was observed.

Then a series of control experiments were performed. Under visible light irradiation (LED, $400-800 \mathrm{~nm}, 30 \mathrm{~W}$ ) using 2 equiv. of $\mathrm{Et}_{3} \mathrm{SiH}, 56 \%$ conversion of $1 \mathrm{a}$ was observed, with a ratio of $>95$ : $<5$ for products 2a: 3a (entry 7). Replacing the UV-LED devices by a Rayonnet RPR100 apparatus (350 nm) had little influence on both reactivity and selectivity (Table S1, entry 17). Noteworthy, under the same conditions, the use of a medium pressure UV mercury lamp ( $150 \mathrm{~W}$ ) led to a $86 \%$ conversion after only 1 h but the selectivity 2a: 3a dropped to 85: 15 (Table S1, entry18). In the absence of any light or under thermal conditions ${ }^{10}\left(100^{\circ} \mathrm{C}\right)$, no conversion of 1 a was detected after 6 $\mathrm{h}$ (entries 8 and 9), demonstrating that the photo irradiation is essential to reduce methyl 2-naphthylacetate $\mathbf{1 a}$.

Having optimized the reduction of $1 \mathrm{a}$ with $\mathrm{Mn}_{2}(\mathrm{CO})_{10}$, we then investigated the catalytic efficiency of the related complex $\operatorname{Re}_{2}(\mathrm{CO})_{10}$, applying the optimized conditions, albeit using a lower loading of catalyst $(0.5 \mathrm{~mol} \%)$ as in the case of carboxylic acids. ${ }^{21} 1$ a was thus quasi-quantitatively converted (96\%) and the corresponding acetal $\mathbf{2} \mathbf{a}$ was obtained in good yield with high selectivity (>95\%, entry 10, more details in S.I. table S2). "On-Off" experiments (see S.I. Figure S1 (Mn) and S2 (Re)) confirmed that continuous irradiation is also mandatory for both reductions to proceed. ${ }^{20}$ In addition, the presence of TEMPO inhibited the reaction with both metals. (See S.I. for complementary experiments and discussion). ${ }^{23}$

With the optimized conditions in hand (Table 1): Method $\mathbf{A}$ $\left(\mathrm{Mn}_{2}(\mathrm{CO})_{10}, 5.0 \mathrm{~mol} \%\right.$, entry 6$)$ or method B $\left(\operatorname{Re}_{2}(\mathrm{CO})_{10}\right.$, 0.5 mol\%, entry 10$), 1.1$ equiv. of $\mathrm{Et}_{3} \mathrm{SiH}$, toluene, room temperature, $9 \mathrm{~h}$, photo irradiation $(365 \mathrm{~nm}, 40 \mathrm{~W})$, we then explored the scope of this transformation (Table 2, and S.I. for limitations). Noteworthy, since the two methods generally give similar results, we will detail below only those obtained with method $\mathbf{A}$. The results observed with method $\mathbf{B}$ will only be mentioned, if there is a significant difference between the two metals. Methyl 2-naphthylacetate 1a, 1-naphthylacetate 1c and 2-phenylacetate $\mathbf{1 e}$ were readily converted into the corresponding alkyl silyl acetals $\mathbf{2 a}, \mathbf{2 c}$ and $\mathbf{2 e}$ in $\mathbf{7 1 - 8 2} \%$ isolated yields. In general, ethyl esters were found to be more reactive than their methylated analogues, as demonstrated with the quantitative reduction of esters $\mathbf{1 b}, \mathbf{1 d}$ and $\mathbf{1 f}$ into the corresponding acetals $\mathbf{2 b}, \mathbf{2} \mathbf{d}$ and $\mathbf{2 f}$ obtained in high yields (9499\%). $p$-, $m$-, o-Methyl substituted 2-phenylacetates $\mathbf{1 g}, \mathbf{1 h}$ and 1i were reduced in reasonable yields (59-83\%). Increasing the steric hindrance at the phenyl ring barely affects the efficiency of this reaction, as illustrated with the ester $\mathbf{2} \mathbf{j}$ featuring a mesityl group formed in $77 \%$ yield. Methyl 2-phenylacetate $\mathbf{1 k}$ bearing a $p$-methoxy substituent and its ethyl analogue $\mathbf{1}$ were smoothly converted into the corresponding alkyl silyl acetals $\mathbf{2 k}$ and $\mathbf{2 l}$ isolated in $87 \%$ and $97 \%$, respectively. From esters bearing halogen atoms (1m-1p), the corresponding products $\mathbf{2 m - 2 p}$ were obtained in moderate to excellent yields (68-99\%). It must be noted that the acetal $\mathbf{2 n}$ decomposed into the corresponding aldehyde $\mathbf{4 h}$ during its purification on silica gel (See also Table 3, entry 8 ). While $\mathrm{Mn}_{2}(\mathrm{CO})_{10}$ afforded product 20 in $59 \%$ yield, no conversion of the ester 10 exhibiting a $p$ bromo substituent was observed with $\operatorname{Re}_{2}(\mathrm{CO})_{10}$, in line with the results obtained for the reduction of carboxylic acids. ${ }^{21}$. However, the reaction is tolerant to an electron-withdrawing group such as a $p$-trifluoromethyl substituent yielding the product $\mathbf{2 p}$ in $75 \%$ yield. Increasing the steric hindrance at the $\alpha$-position of the ester decreased the reactivity, as observed with the methyl 2-phenylbutanoate $\mathbf{1 q}$ converted into $\mathbf{2 q}$ in $68 \%$ yield in the presence of 4 equiv. $\mathrm{Et}_{3} \mathrm{SiH}$. The reactions between $\mathrm{Et}_{3} \mathrm{SiH}$ and methyl/ethyl/benzyl 3-phenylpropanoate substrates $\mathbf{1 r - 1 t}$ afforded the corresponding acetals $\mathbf{2 r - 2 t}$ in $88 \%$, 99\% and 
Table 2. Scope of the catalyzed reduction of carboxylic esters $\mathbf{1}$ to alkyl silyl acetals $\mathbf{2}^{[a]}$

(ofluene, hv (LED $365 \mathrm{~nm})$

[a] General conditions: ester (0.5 mmol), $\mathrm{Et}_{3} \mathrm{SiH}(88 \mu \mathrm{L}, 0.55 \mathrm{mmol}), \mathrm{Mn}_{2}(\mathrm{CO})_{10}(9.8$ $\mathrm{mg}, 5.0 \mathrm{~mol} \%$, method $\mathbf{A})$ or $\operatorname{Re}_{2}(\mathrm{CO})_{10}(1.6 \mathrm{mg}, 0.5 \mathrm{~mol} \%$, method B), r.t., toluene $(1.0 \mathrm{~mL}$ ), irradiation (LED $395 \mathrm{~nm}, 45 \mathrm{~W}), 9 \mathrm{~h}$; Conversion of 1 detected by ${ }^{1} \mathrm{H}$ NMR and isolated yields of $\mathbf{2}$ in parentheses; [b] $1.0 \mathrm{mmol}$ scale, toluene $(1.0 \mathrm{~mL})$; [c] 2.2 equiv. $\mathrm{Et}_{3} \mathrm{SiH} ;$ [d] 4.0 equiv. $\mathrm{Et}_{3} \mathrm{SiH}$; [e] $\mathrm{Mn}_{2}(\mathrm{CO})_{10}\left(10.0\right.$ mol\%); [f] $\operatorname{Re}_{2}(\mathrm{CO})_{10}(1.0$ mol\%).

99\% yields, respectively.

Esters bearing aliphatic chains like methyl decanoate $\mathbf{1} \mathbf{u}$, ethyl acetate $1 \mathbf{v}$ and butyl formate $\mathbf{1 w}$ gave full conversion affording the corresponding products $\mathbf{2 u}$ (method B), $\mathbf{2 v}$ and $\mathbf{2 w}$ in $96 \%$, 99\% and 99\% yields, respectively. Dimethyl tridecanedioate $\mathbf{1 x}$ was proved to be a suitable substrate since diacetal $\mathbf{2 x}$ was formed in $92 \%$ isolated yield with 2.2 equiv. of $\mathrm{Et}_{3} \mathrm{SiH}$ and $\operatorname{Re}_{2}(\mathrm{CO})_{10}(1.0 \mathrm{~mol} \%)$. The internal $\mathrm{C}=\mathrm{C}$ bond in methyl oleate $1 \mathrm{y}$ was also tolerated, as the acetal $\mathbf{2 y}$ was produced in $56 \%$ yield with the $\mathrm{C}=\mathrm{C}$ bond remaining intact. ${ }^{24}$ On the opposite, when methyl 5-hexynoate was engaged as substrate, even in the presence of 2 equiv. of $\mathrm{Et}_{3} \mathrm{SiH}$, the hydrosilylation took place only at the terminal triple bond in line with the results reported by Wang and coll. ${ }^{25}$ Good isolated yields were generally obtained from benzoate derivatives: methyl and ethyl benzoate (1z, 1z') and ethyl 4-methoxybenzoate 2aa were thus transformed into the acetals 2z, 2z' and $\mathbf{2}$ aa in 99\%, 75\% and
Table 3. Scope of the reduction of carboxylic esters 1 to aldehydes $4 .{ }^{\text {[a] }}$

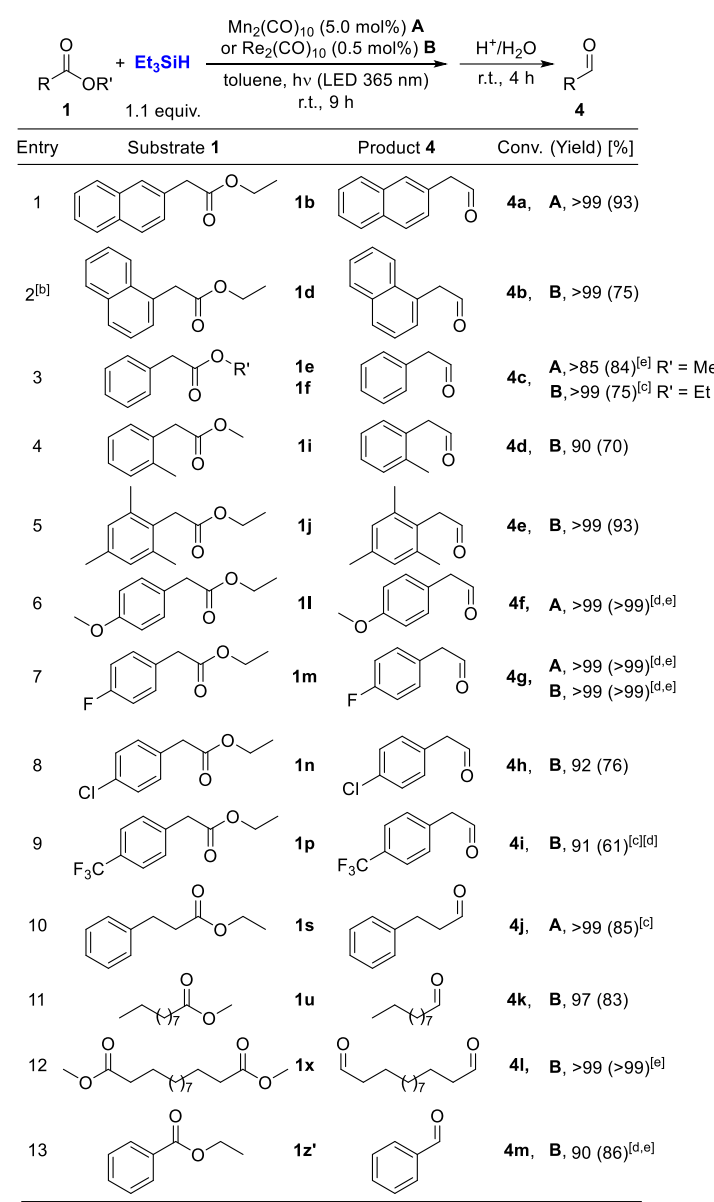

[a] General conditions: ester ( $0.5 \mathrm{mmol}), \mathrm{Et}_{3} \mathrm{SiH}(88 \mu \mathrm{L}, 0.55 \mathrm{mmol}), \mathrm{Mn}_{2}(\mathrm{CO})_{10}(9.8$ $\mathrm{mg}, 5.0 \mathrm{~mol} \%$, method $\mathbf{A}$ ) or $\operatorname{Re}_{2}(\mathrm{CO})_{10}(1.6 \mathrm{mg}, 0.5 \mathrm{~mol} \%$, method $\mathbf{B})$, r.t., toluene $(1.0 \mathrm{~mL}$ ), irradiation (LED $395 \mathrm{~nm}, 45 \mathrm{~W}), 9 \mathrm{~h}$; then hydrolysis (THF/HCl $1 \mathrm{~N}), 4 \mathrm{~h}$. Conversions of $\mathbf{1}$ detected by ${ }^{1} \mathrm{H}$ NMR and isolated yields of $\mathbf{4}$ in parentheses; [b] $4.67 \mathrm{mmol}$ (1 gram) scale; [c] Isolated as solid trioxane derivatives, see S.I.; [d] 1.0. $\mathrm{mmol}$ scale, toluene $(1.0 \mathrm{~mL})$, [e] NMR yield determined with internal standard.

95\% yields with $\mathrm{Mn}_{2}(\mathrm{CO})_{10}$. With $\mathrm{Re}_{2}(\mathrm{CO})_{10}$ slightly lower conversions were observed for $\mathbf{2 z}$ and $\mathbf{2 a a}$ (75\% and 90\%, respectively). Methyl 4-chlorobenzoate $\mathbf{1}$ ab was reduced with a conversion of $37 \%$ and $80 \%$, by using $\mathrm{Mn}$ and $\mathrm{Re}$ basedcatalysts, respectively. Heteroaromatic substrates such as methyl (or ethyl) furan-2-carboxylate 1ac (1ad) can be transformed into 2 ac (2ad) in 40\% (96\%) isolated yield.

In order to directly obtain the aldehyde products from the esters, we then performed an one-pot synthesis consisting in carrying out the hydrosilylation of the esters followed by the acidic hydrolysis of the acetals formed into aldehydes. The general scope of the present reaction is presented on Table 3. Overall, the ester substrates were readily converted under standard conditions. For instance, the 2-(2naphthalenyl)acetaldehyde 4 a was isolated in $93 \%$ yield, with $\mathrm{Mn}_{2}(\mathrm{CO})_{10}$ as catalyst. Furthermore, from ethyl 2-(1naphthalenyl)acetate $\mathbf{1 d}$, we have demonstrated the synthetic utility of this methodology in the preparation of aldehyde in gram scale, as evidenced with the corresponding aldehyde $\mathbf{4 b}$ produced in $75 \%$ yield after purification by bulb to bulb 
distillation. In addition, 2-phenylacetaldehyde $4 \mathbf{c}$ and its derivatives bearing methyl- $\mathbf{4 d}, \mathbf{4 e}$, methoxy- $\mathbf{4 f}$, fluoro- $\mathbf{4 g}$, chloro- $\mathbf{4 h}$ and trifluoromethyl- $\mathbf{4 i}$ groups were isolated in 61$\mathbf{9 3} \%$ yields. 3 -Phenylpropanal $\mathbf{4 j}$, decanal $\mathbf{4 k}$, tridecandial $\mathbf{4 I}$ and benzaldehyde $4 \mathrm{~m}$ could also be prepared in over $80 \%$ yields. In conclusion, the first $\mathrm{Mn}$-catalyzed hydrosilylation of esters into corresponding silylacetals was carried out under mild conditions with excellent yield and high chemoselectivity. In addition, an alternative Re-based catalyst was considered showing comparable results for the same transformation. The two simple catalytic systems are based on commercially available $\mathrm{Mn}_{2}(\mathrm{CO})_{10} \quad\left(5.0 \mathrm{~mol} \%\right.$ ) or $\operatorname{Re}_{2}(\mathrm{CO})_{10} \quad(0.5 \mathrm{~mol} \%)$ complexes in the presence of a stoichiometric amount of $\mathrm{Et}_{3} \mathrm{SiH}$ (1.1 equiv.) as an inexpensive silane source. With both catalysts, at room temperature under irradiation at $365 \mathrm{~nm}$ (LED, 4*10W), a large variety of carboxylic esters was thus reduced in moderate to good yields to the corresponding protected aldehydes without noticeable formation of silylethers arising from over-reduction. Upon hydrolysis, aromatic and aliphatic aldehydes, including di-aldehydes, were easily produced and isolated in good yields. For future developments in this competitive field, the two metallic systems reported here will have to be envisaged in a complementary manner, the catalytic loading 10 times lower used with rhenium having to be opposed with the lower price of manganese.

\section{Conflicts of interest}

There are no conflicts to declare.

\section{Notes and references}

1 a) L. I. Zakharkin, V. V. Gavrilenko, D. N. Maslin and I. M. Khorlina, Tetrahedron Lett., 1963, 4, 2087-2090; b) P. M. Weissman and H. C. Brown, J. Org. Chem., 1966, 31, 283-287; c) M. S. Kim, Y. M. Choi and D. K. An, Tetrahedron Lett., 2007, 48, 5061-5064; d) M. Masayoshi and M. Teruaki, Chem. Lett., 1975, 4, 215-218; e) J. S. Cha and S. S. Kwon, J. Org. Chem. 1987, 52, 5486-5487; f) N. M. Yoon, J. H. Ahn, D. K. An and Y. S. Shon, J. Org. Chem., 1993, 58, 1941-1944.

2 L. I. Zakharkin and I. M. Khorlina, Tetrahedron Lett., 1962, 3, 619-620.

3 A. Feinstein and E. K. Fields, U.S. Patent 3,935,265, 1976.

4 S. T. King and E. J. Strojny, J. Catal., 1982, 76, 274-284.

5 a) A. Chen, H. Xu, W. Hua, W. Shen, Y. Yue and Z. Gao, Top. Catal., 2005, 35, 177-185; b) H.-L. Xu, W. Shen and Y.-T. Yang, Chin. J. Chem., 2001, 19, 647-651; c) C. Pan, G. Chen, W. Shen and H. Xu, Catal. Commun., 2009, 10, 1718-1721; d) A. Chen, H. Xu, Y. Yue, W. Hua, W. Shen and Z. Gao, Appl Catal A: Gen, 2004, 274, 101-109.

6 D. Addis, S. Das, K. Junge and M. Beller, Angew. Chem. Int. Ed. 2011, 50, 6004-6011.

7 S. Hosokawa, M. Toya, A. Noda, M. Morita, T. Ogawa and Y. Motoyama, ChemistrySelect, 2018, 3, 2958-2961.

8 a) D. J. Parks and W. E. Piers, J. Am. Chem. Soc., 1996, 118 9440-9441; b) D. J. Parks, J. M. Blackwell and W. E. Piers, J. Org. Chem., 2000, 65, 3090-3098.

9 J. Nakanishi, H. Tatamidani, Y. Fukumoto and N. Chatani, Synlett, 2006, DOI: 10.1055/s-2006-939058, 869-872.

10 M. Igarashi, R. Mizuno and T. Fuchikami, Tetrahedron Lett., 2001, 42, 2149-2151.
11 a) C. Cheng and M. Brookhart, Angew. Chem. Int. Ed., 2012 51, 9422-9424; b) Y. Corre, V. Rysak, F. Capet, J.-P. Djukic, F. Agbossou-Niedercorn and C. Michon, Chem. Eur. J., 2016, 22 , 14036-14041.

12 V. Rysak, A. Descamps-Mandine, P. Simon, F. Blanchard, L. Burylo, M. Trentesaux, M. Vandewalle, V. Collière, F. Agbossou-Niedercorn and C. Michon, Catal. Sci. Technol., 2018, 8, 3504-3512.

13 H. Li, L. C. Misal Castro, J. Zheng, T. Roisnel, V. Dorcet, J.-B. Sortais and C. Darcel, Angew. Chem. Int. Ed., 2013, 52, 80458049.

14 a) D. A. Valyaev, G. Lavigne and N. Lugan, Coord. Chem. Rev., 2016, 308, 191-235; b) W. Liu and L. Ackermann, ACS Catal., 2016, 6, 3743-3752; c) Y. Hu, B. Zhou and C. Wang, Acc. Chem. Res., 2018, 51, 816-827.

15 F. Kallmeier and R. Kempe, Angew. Chem. Int. Ed., 2018, 57 46-60.

16 a) S. Elangovan, M. Garbe, H. Jiao, A. Spannenberg, K. Junge and M. Beller, Angew. Chem. Int. Ed., 2016, 55, 15364-15368; b) N. A. Espinosa-Jalapa, A. Nerush, L. J. W. Shimon, G. Leitus, L. Avram, Y. Ben-David and D. Milstein, Chem. Eur. J., 2017, 23, 5934-5938; c) R. van Putten, E. A. Uslamin, M. Garbe, C. Liu, A. Gonzalez-de-Castro, M. Lutz, K. Junge, E. J. M. Hensen, M. Beller, L. Lefort and E. A. Pidko, Angew. Chem. Int. Ed., 2017, 56, 7531-7534; d) M. B. Widegren and M. L. Clarke, Org. Lett., 2018, 20, 2654-2658.

17 a) R. J. Trovitch, Acc. Chem. Res., 2017, 50, 2842-2852; b) X. Yang and C. Wang, Chem. Asian J., 2018, 13, 2307-2315; c) B. Royo, Adv. Organomet. Chem., 2019, 72, 59-102.

18 a) O. Martínez-Ferraté, B. Chatterjee, C. Werlé and W. Leitner, Catal. Sci. Technol., 2019, 9, 6370-6378; b) T. K. Mukhopadhyay, C. Ghosh, M. Flores, T. L. Groy and R. J. Trovitch, Organometallics, 2017, 36, 3477-3483; c) T. K. Mukhopadhyay, M. Flores, T. L. Groy and R. J. Trovitch, J. Am. Chem. Soc., 2014, 136, 882-885; d) C. M. Kelly, R. McDonald, O. L. Sydora, M. Stradiotto and L. Turculet, Angew. Chem. Int. Ed., 2017, 56, 15901-15904.

19 Z. Mao, B. T. Gregg and A. R. Cutler, J. Am. Chem. Soc., 1995, 117, 10139-10140.

20 Fan and coll. already reported that Re carbonyl complexes such as $\operatorname{Re}(\mathrm{CO})_{5} \mathrm{Cl}$ and $\mathrm{Re}_{2}(\mathrm{CO})_{10}$ catalyses the hydrosilylation of ethyl acetate to the corresponding silyl ether under photochemical activation (200 - $800 \mathrm{~nm}$ ). Acetaldehyde was identified as the intermediate. See: C. K. Toh, Y. N. Sum, W. K. Fong, S. G. Ang and W. Y. Fan, Organometallics 2012, 31, 3880-3887.

21 D. Wei, R. Buhaibeh, Y. Canac and J.-B. Sortais, Org. Lett. 2019, 21, 7713-7716.

22 a) J. Zheng, S. Chevance, C. Darcel and J.-B. Sortais, Chem Commun., 2013, 49, 10010-10012; b) L. C. Misal Castro, H. Li, J.-B. Sortais and C. Darcel, Chem. Commun., 2012, 48, 1051410516.

23 a) M.-A. Tehfe, J. Lalevée, D. Gigmes and J. P. Fouassier, J. Polym. Sci., Part A: Polym. Chem., 2010, 48, 1830-1837; b) M. S. Wrighton and D. S. Ginley, J. Am. Chem. Soc., 1975, 97, 2065-2072; c) D. M. Allen, A. Cox, T. J. Kemp, Q. Sultana and R. B. Pitts, J. Chem. Soc., Dalton Trans., 1976, DOI: 10.1039/DT9760001189, 1189-1193; d) S. A. Hallock and A. Wojcicki, J. Organomet. Chem., 1973, 54, C27-C29.

24 a) X. Yang and C. Wang, Chin. J. Chem., 2018, 36, 1047-1051 b) S. L. Pratt and R. A. Faltynek, J. Organomet. Chem., 1983 , 258, C5-C8; c) H. S. Hilal, M. Abu-Eid, M. Al-Subu and S. Khalaf, J. Mol. Catal., 1987, 39, 1-11; d) H. S. Hilal, M. A. Suleiman, W. J. Jondi, S. Khalaf and M. M. Masoud, J. Mol. Catal. A: Chem., 1999, 144, 47-59.

25 X. Yang and C. Wang, Angew. Chem. Int. Ed., 2018, 57, 923 928. 